\title{
Mediastinal thoracic duct cyst
}

\section{F J SAMBROOK GOWAR}

From the Department of Thoracic Surgery, Aberdeen Royal Infimary, Aberdeen $A B 92 Z B, U K$

Sambrook Gowar, F J (1978). Thorax, 33, 800-802. Mediastinal thoracic duct cyst. A case of mediastinal thoracic duct cyst is described; it is believed to be the first to be reported in Britain.

Five surgically treated cases have been reported but in none was the diagnosis made before operation. Symptoms are caused by pressure of the cyst on the trachea and oesophagus and may be aggravated by eating a fatty meal. Differential diagnosis from other mediastinal tumours, especially bronchogenic cyst and neurofibroma, could perhaps be established before operation by lymphangiography.

\section{Case report}

A 45-year-old housewife who had had an attack of influenza three months previously, complained of dyspnoea on exertion, spasmodic cough occasionally productive of yellow sputum, and difficulty in swallowing, solids tending to stick in her throat at the level of the sternal notch. There had been a little huskiness of the voice.

There was a history of actinomycosis of the neck at the age of 32 , which had healed after drainage and radiotherapy.

The patient was overweight and had a bovine cough and some inspiratory and expiratory stridor. The lungs were clear except for a few scattered rhonchi, and no abnormality was found in the

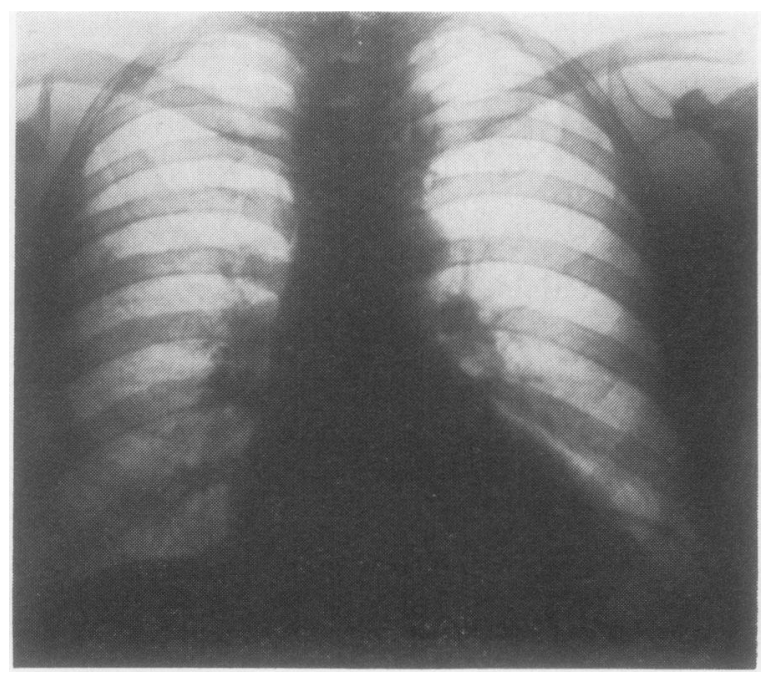

heart or abdomen. Blood pressure was $150 / 90$ mmHg. There was a well-healed scar in the neck across the left sternomastoid muscle and postradiation telangiectasis of the left side of the neck.

A chest radiograph showed an ovoid mass in the left superior mediastinum lying above the aortic arch and behind an anteriorly displaced and slightly compressed trachea (fig 1). Barium $\unrhd$ swallow showed delay at the suprasternal notch $\overrightarrow{\vec{O}}$ where the oesophagus took a short turn forwards 3 and to the right round the mass, which did not pulsate. Endoscopy showed some bulging of the posterior wall of the oesophagus at $15 \mathrm{~cm}$ by an extrinsic mass and a little tracheal narrowing as if by external constriction; no bronchial or oeso- ? phageal neoplasm was evident.

Fig 1 Chest radiograph $(P A)$ showing ovoid opacity above aortic knuckle. 
The most likely diagnosis was thought to be a tracheal cyst, and on 1 August 1949 left thoracotomy was performed. A cystic tumour was found above the aortic arch displacing the subclavian artery forwards. The thoracic duct ran into the lower pole of the tumour and out at the upper pole. The cyst was separated by blunt dissection and removed after doubly ligating and dividing the thoracic duct above and below. During the dissection milky fluid leaked from the cyst. The postoperative course was smooth, and the patient was discharged 16 days later. When last seen, three years after the operation, she had no complaints, and her chest was clear clinically and radiologically.

\section{PATHOLOGY}

The specimen was a thin-walled unilocular cyst with a well-defined duct running along its wall from the inferior to the superior pole (fig 2). A probe passed along the duct entered the cyst through a defect in the duct wall. The wall of the cyst was composed of relatively avascular connective tissue with areas showing low-grade chronic inflammatory changes. There was no recognisable lining to the cyst wall-occasionally a few flattened "endothelial" cells were seen but these were not conspicuous. The duct structures were well defined and formed by connective tissue and smooth muscle with an endothelial lining just visible in some fields. The pathologist concluded: "It seems beyond any reasonable doubt that this is a cyst of the thoracic duct. It is quite benign."

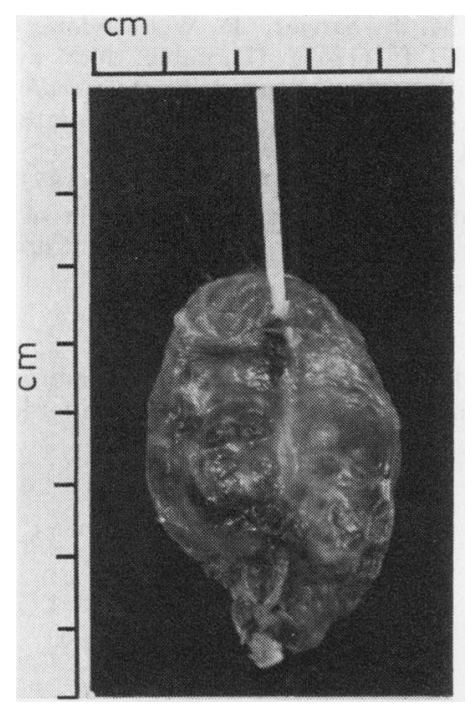

Fig 2 Photograph of cyst after removal with probe in thoracic duct.
DISCUSSION

Although lymphatic cysts are not uncommonly found in the neck and other areas, there are very few reports of thoracic duct cysts. Cysts may occur at any level, but in this report only those occurring in the thorax are considered. Carbone (1892) was the first to report a case of supradiaphragmatic thoracic duct cyst, which was found incidentally at a necropsy on a 50-year-old woman. Emerson (1950) reported the first case diagnosed during life. He was able to find only seven necropsy reports of thoracic duct cysts, three below and four above the diaphragm, two of the latter being multiple. Since 1950 four additional cases treated surgically have been reported.

Emerson's (1950) patient was a 20-year-old female student with a history of recurrent attacks of substernal soreness, exertional dyspnoea, and non-productive cough for two-and-a-half-years with aggravation for five months. The chest radiograph showed a smooth ovoid mass behind the right hilum with atelectasis of the apical segment of the right lower lobe and indentation of the oesophagus on the barium swallow. At operation a cyst $5.5 \times 4 \mathrm{~cm}$ was removed from the posterior mediastinum; the thoracic duct was identified entering and leaving the cyst.

Bakst (1954) reported the case of an epiphrenic cyst that communicated with the thoracic duct below and behind the diaphragm but ended blindly above. The lesion was found on radiological examination of a 42-year-old man who complained of right upper abdominal pain, but removal of the cyst failed to relieve the pain.

Thomas et al (1963) reported the case of an asymptomatic man of 43 who was found on routine chest radiology to have a $4 \mathrm{~cm}$ rounded opacity overlapping the aortic knuckle. At operation a chylous cyst was found in the posterior mediastinum above the aortic arch and medial to the left subclavian artery. A small pedicle from the thoracic duct entered the base of the cyst.

The case of Fromang et al (1975) was a woman of 35 who had complained of chest discomfort, dry cough, and wheezing for one month. Radiological examination showed a large posterior mediastinal mass that pushed forward and compressed the trachea and oesophagus, and there was partial obstruction of the superior vena cava. Lymphoma was diagnosed provisionally, and a course of radiotherapy was given before operation. After eating a fatty meal there was an episode of acute respiratory obstruction that required emergency endotracheal intubation and precipitated surgical treatment. At operation a unilocular cyst $15 \times 10 \times 10 \mathrm{~cm}$ was removed from the upper pos- 
terior mediastinum. It contained chyle and was continuous with the thoracic duct below, but no communication was shown above.

Cervantes-Perez and Fuentes-Maldonado (1976) reported the case of a man of 42 who complained of retrosternal pain after meals for three years. At operation a yellowish smooth-walled tumour with no identifiable pedicle was removed from the posterior mediastinum. It lay behind the heart and caused forward compression and displacement of the oesophagus. On section it was a thick-walled trabeculated lesion $12 \times 8 \times 3 \mathrm{~cm}$ containing fibrin and milky fluid. After operation the patient developed a chylothorax. Cervantes-Perez and Fuentes-Maldonado emphasised the importance of postprandial chest pain or symptoms of mediastinal compression in close relation to eating a meal in the diagnosis of thoracic duct cyst and recommended lymphangiography to confirm the diagnosis.

\section{Aetiology}

Ross (1961) in a review of the surgery of the thoracic duct described two varieties of thoracic duct cysts-the degenerative and the lymphangiomatous. Cysts of the degenerative variety are nearly always found incidentally in the elderly at necropsy. The degenerative changes that occur in the duct wall have been likened to those occurring in the walls of aging peripheral veins (Kausel et al, 1957). Atherosclerotic plaque formation and calcification have been recorded in some cases, and the cysts may be multiple.

Benign lymphangiomata arising in the thoracic duct may also produce single or multiple cyst-like spaces filled with chyle, a more extensive variant being the mediastinal hygroma (Touroff and Seeley, 1953). Such cysts are more likely to rupture into the pleura than the degenerative ones and are a rare cause of spontaneous chylothorax (Maurer, 1956). They are normally found in younger people.

The average age of the six recorded surgical cases is $38(20-45)$-younger than would be expected if degenerative changes were responsibleand in all the cyst was solitary. It would seem reasonable to postulate a congenital weakness or deficiency of the duct wall that gradually gives way forming a localised aneurysm or ruptures to produce a spontaneous chylothorax. In the present case it is speculative whether the earlier actinomycotic infection of the neck had any aetiological relationship to the development of the cyst.

I am indebted to Professor A L Stalker for the pathology report.

\section{References}

Bakst, A A (1954). Blind supradiaphragmatic thoracic duct cyst: case. Annals of Surgery, 140, 250-253.

Carbone, T (1892). Cisti del dotto toracico. Giornale della $R$ Accademia di Medicina di Torino, 40, 136144.

Cervantes-Perez, P, and Fuentes-Maldonado, R (1976). Letter-Thoracic Dust Cyst of the Mediastinum Chest, 70, 411.

Emerson, G L (1950). Supradiaphragmatic thoracic duct cyst. New England Journal of Medicine, 242, 575-578.

Fromang, D R, Seltzer, M B, and Tobias, J A (1975). Thoracic duct cyst causing mediastinal compression and acute respiratory insufficiency. Chest, 67, 725727.

Kausel, H W, Reeve, T S, Stein, A A, Alley, R D and Stranahan, A (1957). Anatomic and pathologic studies of the thoracic duct. Journal of Thoracic and Cardiovascular Surgery, 34, 631-642.

Maurer, E R (1956). Complete extirpation of thoracic duct: Use in management of primary benign tumour producing spontaneous chylothorax. Journal of the American Medical Association, 161, 135-138.

Ross, J K (1961). A review of the surgery of the thoracic duct. Thorax, 16, 12-21.

Thomas, M J, Sanger, $P$ W, Taylor, F H, and Robicsek, F (1963). Thoracic duct cyst of the mediastinum. In Collected Works Cardiopulmonary Disease. Heineman Foundation Laboratories, Charlotte NC, 7, 541-543.

Touroff, A S W, and Seeley, G P (1953). Chronic chylothorax associated with hygroma of the mediastinum. Journal of Thoracic and Cardiovascular Surgery, 26, 318-320.

Requests for reprints to: Mr F J Sambrook Gowar, Department of Thoracic Surgery, Aberdeen Royal Infirmary, Aberdeen AB9 2ZB. 